Scientific Research and Essays Vol. 6(19), pp. 4113-4124, 8 September, 2011

Available online at http://www.academicjournals.org/SRE

DOI: $10.5897 /$ SRE 11.674

ISSN 1992-2248 @2011 Academic Journals

Full Length Research Paper

\title{
Equilibrium, thermodynamic and kinetics of reactive black 5 biosorption on loquat (Eriobotrya japonica) seed
}

\author{
Handan UCUN \\ Department of Environmental Engineering, Faculty of Engineering, Bartin University, \\ 74100 Bartin, Turkey. \\ Accepted 28 July, 2011
}

\begin{abstract}
Biosorption is an alternative process for uptake of reactive dyes from aqueous solution. In the present study, the biosorption of reactive black 5 (RB 5 ) from aqueous solution was investigated by using loquat (Eriobotrya japonica) seed biosorbent in a batch adsorption technique as a function of contact time $(0.5 \mathrm{~min}$ to $3 \mathrm{~h}$ ), initial dye concentration (50 to $200 \mathrm{mg} / \mathrm{L})$, biosorbent dose (5 to $30 \mathrm{~g} / \mathrm{L}$ ) and $\mathrm{pH}(1.5$ to 5.5). The experimental data showed that the optimum pH for efficient biosorption of RB 5 was 2.5. The data were analyzed on the basis of Lagergren pseudo-first-order, pseudo-second-order, Elovich equation and Weber-Morris kinetic models tested. The results suggested that the pseudo-second-order model $(R>0.999)$ was the best choice among all the kinetic models to describe the biosorption behavior of RB 5 onto the biosorbent. The equilibrium data were evaluated by using Langmuir and Freundlich isotherms and the Langmuir isotherm was found to provide the best correlation of the experimental data. Thermodynamic parameters including the Gibbs free energy $\left(\Delta G^{\circ}\right)$, enthalpy $\left(\Delta H^{\circ}\right)$ and entropy $\left(\Delta S^{\circ}\right)$ changes indicated that the biosorption of RB 5 onto loquat seed biosorbent was feasible, spontaneous and endothermic. The results revealed that loquat seed biosorbent could be used as biosorbent for the treatment of wastewater containing RB 5.
\end{abstract}

Key words: Biosorption, isotherm, loquat seed, reactive black 5, thermodynamic.

\section{INTRODUCTION}

A dye is described as a colored substance with affinity to substrate applied. In many industrial areas including textile, plastics, wool, paper, cotton and silk dyes are widely used to color the products. Based on the origin and complex molecular structure, dyes can be classified as anionic-direct, acid and reactive dyes, cationic-basic dyes and non-ionic-disperse dyes (Mishra and Tripathy, 1993; Fu and Viraraghavan, 2001). Reactive dyes, which

*Corresponding author. E-mail: hanucun@yahoo.com. Tel: +90 378223 5361. Fax: +90 3782235258. are typically azo-based chromophores combined with different types of reactive groups for example, vinyl sulfone, chlorotriazine, trichloropyrimidine, difluorochloropyrimidine (Sadettin and Dönmez, 2006) are extensively used in many areas of textile because of their favorable characteristics such as bright color, waterfast soluble and simple application techniques (Vijayaraghavan and Yun, 2008). On the other hand, they are common water pollutants and can frequently be found in industrial wastewater because of their good solubility. Furthermore, the presence of reactive dyes in aquatic systems can cause serious harmful effects on the aquatic life by increasing toxicity and chemical oxygen demand 
and by hindering photosynthetic activity (Robinson et al., 2001). It is known that majority of these dyes are synthetic in nature and are usually composed of aromatic rings in their structure which makes them carcinogenic and mutagenic for aquatic biota (Wang et al., 2005; Hameed et al., 2008). Hence, the removal of reactive dyes from wastewaters is an important strategy to maintain the aquatic life. Common physical and chemical procedures for reactive dyes removal from industrial wastewaters include coagulation, precipitation, adsorption, reverse osmosis and ion exchange. However, their widespread use is restricted due to requiring additional chemical, high cost and energy consumption. For this reason, the research activities have been focused on biological methods (Parasad and Freitas, 2003) owing to their three main advantages for the removal of pollutants.

The first one, biological processes can be applied in situ at the contaminated site; secondly, bioprocess technologies are usually environmentally benign (no secondary pollution) and thirdly, they are cost effective (Vijayaraghavan and Yun, 2008). Among different biological methods, bioaccumulation and biosorption have been shown to possess good potential to replace conventional methods for the removal of dyes. Biosorption is a technique that can be used for the removal of pollutants like metals and dyes from wastewaters. A variety of biomaterials are known to bind these pollutants including bacteria, fungi, algae, and industrial and agricultural wastes. In recent years, agricultural wastes such as neem oil cake (Rao and Khan, 2009), loquat seed (Aksakal et al., 2009), pine sawdust (Özacar and Sengil, 2005), rice husk (Chowdhury and Sarakar, 2009), and palm kernel seed coat (Oladoja and Akinlabi, 2009) are used as biosorbent in order to remove pollutants in wastewater. Eriobotrya japonica (loquat) is an evergreen tree of the Maloidae subfamily of the Rosaceae family. Loquat species originated in China, later was introduced in Japan (Zhang et al., 1993). From Japan the species was introduced to the Mediterranean countries. It is cultivated as well in tropical and subtropical countries (Femenia et al., 1998). The world production of loquat in 2006 is estimated at 550.000 tonnes (Lin, 2007). Loquat fruits, growing in clusters are oval, rounded or pear shaped 3 to $5 \mathrm{~cm}$ long, yellow or orange color. Fruits can be consumed fresh or processed and can be used for jam, juice or syrup. Each fruit contains five ovules; of which one to five mature into large brown seeds. Seeds are rich in starch (20\%) and have been used to make wine. The seeds of loquat have been reported to be a source of $(R)$ - hydroxynitrile lyase for synthesis of cyanohydrins (Lin et al., 1999).
The aim of this study was to investigate the potential of using loquat seed as a new low-cost biosorbent for the removal of RB 5 from aqueous solutions. The effects of solution $\mathrm{pH}$, contact time, biosorbent dose and initial dye concentrations on RB 5 removal efficiency were studied. Langmuir and Freundlich isotherms were employed to quantify the adsorption equilibrium. The results were analyzed on the basis of Lagergren pseudo-first-order, pseudo-second-order kinetic, Elovich and Weber-Morris intraparticle diffusion model. Further the thermodynamic parameters $\left(\Delta G^{\circ}, \Delta H^{\circ}, \Delta S^{\circ}\right)$ were also determined.

\section{MATERIALS AND METHODS}

Loquat seeds used as biosorbent in this study were collected in June 2008. They were washed repeatedly with deionized water to remove the adhering dirt and soluble impurities, dried at $80^{\circ} \mathrm{C}$ for 24 $\mathrm{h}$ and then crushed. The dried biosorbent was ground in a mortar to a very fine powder and sieved through a 400-mesh copper sieve. The powdered biosorbent was stored in glass bottles prior to use. The textile dye, reactive black 5, was obtained from Dystar, Turkey and used without further purification. Its chemical structure is shown in Figure 1. By dissolving RB 5 in deionized water, the dye containing stock solution $(1000 \mathrm{mg} / \mathrm{L})$ was obtained. The other required concentrations ( 50 to $200 \mathrm{mg} / \mathrm{L}$ ) were prepared by diluting the stock solution of RB 5. Fresh dilutions were used for each experiment. The $\mathrm{pH}$ of the working solutions was adjusted to desired values with dilute $\mathrm{HCl}$ or $\mathrm{NaOH}$.

\section{Batch biosorption studies}

The experiments were conducted in $250 \mathrm{ml}$ Erlenmeyer flasks containing $100 \mathrm{ml}$ of dye solutions. The effect of $\mathrm{pH}$ on the biosorption process was investigated at different $\mathrm{pH}$ values ranging from 1.5 to 5.5. The effect of biosorbent dosage on RB 5 biosorption was investigated using biosorbent sampling ranging from 5 to $30 \mathrm{~g} / \mathrm{L}$. To determine the effect of initial dye concentration of RB 5, the concentration of dye ranging from 50 to $200 \mathrm{mg} / \mathrm{L}$ was prepared and used. The batch experiments were performed under shaking speed of $200 \mathrm{rpm}$ at $25^{\circ} \mathrm{C}, \mathrm{pH} 2.5$ for $180 \mathrm{~min}$. RB 5 biosorption equilibrium over a temperature range of 25 to $45^{\circ} \mathrm{C}$ was modeled by using the Freundlich and Langmuir models. Kinetic and thermodynamic parameters for the biosorption process were evaluated. After the biosorption process, the solution was centrifuged for $5 \mathrm{~min}$ at $4500 \mathrm{rpm}$ and supernatants were analyzed for remaining dye concentration using a spectrophotometer (597 $\mathrm{nm}$ ) (Shimadzu UV-160A). The amounts of biosorbed RB $5\left(q_{e}\right)$ was calculated as follows:

$q_{e}=\frac{\left(C_{o}-C_{e}\right) \cdot V}{m}$

Where $q_{e}$ is the amount of RB 5 adsorbed per gram of adsorbent $(\mathrm{mg} / \mathrm{g}) . C_{o}$ and $C_{e}$ are the initial and equilibrium dye concentrations $(\mathrm{mg} / \mathrm{L}), \quad V$ is the volume of the dye solution ( $L$ ) and $m$ is the adsorbent mass $(\mathrm{g})$. 


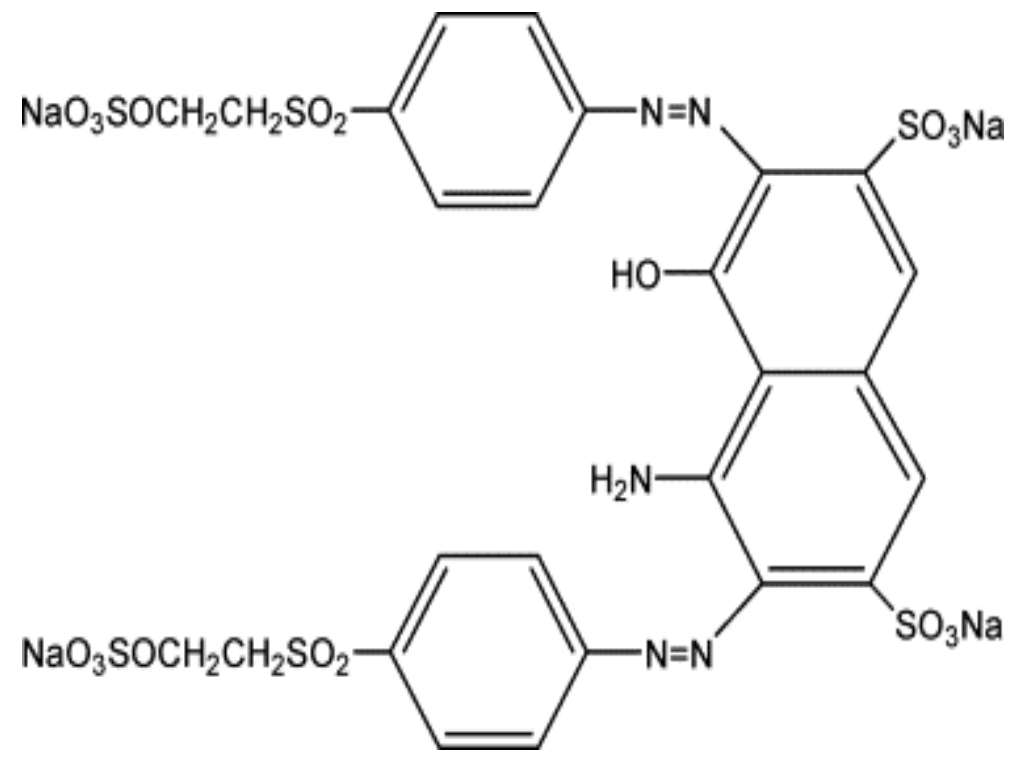

Figure 1. Chemical structure of RB 5.

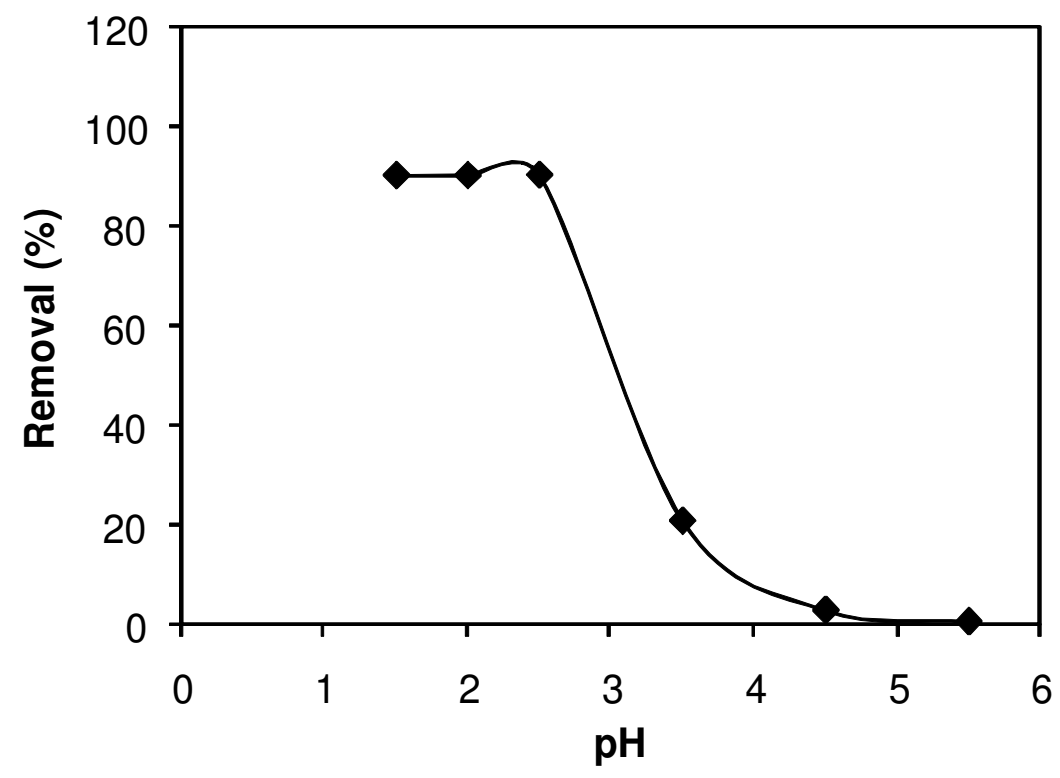

Figure 2. Effect of $\mathrm{pH}$ on RB 5 biosorption efficiency $\left(\mathrm{C}_{0}=50 \mathrm{mg} / \mathrm{L}, \mathrm{m}=10 \mathrm{~g} / \mathrm{L}\right)$.

\section{RESULTS AND DISCUSSION}

\section{Effect of pH}

The effect of initial $\mathrm{pH}$ on the biosorption of dye by loquat seed was studied by varying the $\mathrm{pH}$ of the dye solution from 1.5 to 5.5 for an initial concentration of $50 \mathrm{mg} / \mathrm{L}$.
Figure 2 indicates that the $\mathrm{pH}$ significantly affected the biosorption of the RB 5 onto loquat seed. As shown in the figure, the removal percentage decreased from 90.28 to $0.88 \%$, when the solution $\mathrm{pH}$ changed from 1.5 to 5 . Maximum biosorption was observed at $\mathrm{pH}=2.5$. Then, in the further experiments, the $\mathrm{pH}$ value was fixed as 2.5. The electrostatic interactions between negatively charge 


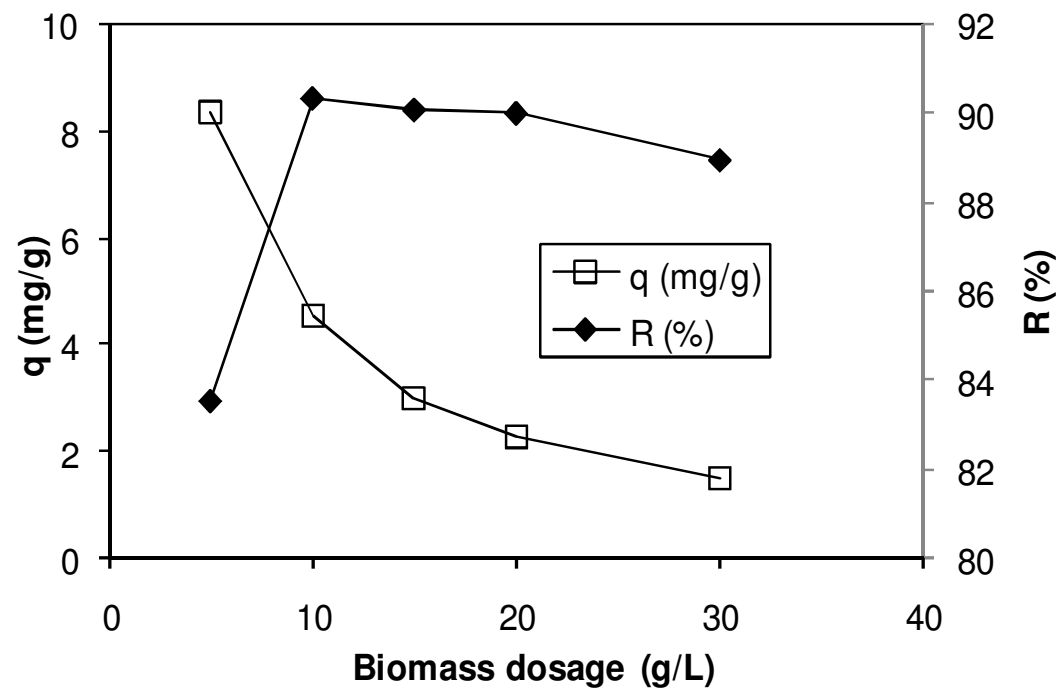

Figure 3. Effect of biosorbent dosage on biosorption efficiency of loquat seed for $\mathrm{RB} 5\left(\mathrm{pH}=2.5, \mathrm{C}_{0}=50 \mathrm{mg} / \mathrm{L}\right)$.

dye anion and positively charged biosorbent surfaces may cause higher uptake rates obtained at lower $\mathrm{pH}$ values. As the initial $\mathrm{pH}$ of the solution increases, the number of negatively charged sites may be increases. A negatively charged surface site on the biosorbent does not favor the adsorption of dye anions due to the electrostatic repulsion. Similar results have been observed by investigators studying on different biosorbents such as Laminaria sp. (Vijayaraghavan and Yun, 2008), wheat bran (Cicek et al., 2007), Nymphaea rubra (Renganathan et al., 2009), Pinus sylvestris cones (Aksakal and Ucun, 2010) and sugar beet pulp (Aksu and Isoglu, 2006).

\section{Effect of biosorbent dose}

Biosorbent dose is a significant factor considered as an effective dye biosorption. The influence of biosorbent dose on the removal of RB 5 was studied using loquat seed biosorbent in the range of 5 to $30 \mathrm{~g} / \mathrm{L}$ and at the initial dye concentration of $50 \mathrm{mg} / \mathrm{L}$. The biosorption capacities and removal efficiency of the loquat seed biosorbent were shown in Figure 3. As shown in Figure 3, the biosorption capacities of the loquat seed biosorbent decreased as the biosorbent dose increased from 5 to 30 $\mathrm{g} / \mathrm{L}$. Removal efficiency increased from 83.52 to $90.36 \%$ as the biosorbent dose increased from 5 to $10 \mathrm{~g} / \mathrm{L}$. Further increases in biosorbent dosage reduced the maximum removal of RB 5 . This can be explained by forming aggregates during biosorption which takes place at high biosorbent concentrations causing a decrease in the effective biosorption area (Ozacar and Sengil, 2005; Oladoja and Akinlabi, 2009). Therefore, in the further experiments, the biosorbent dose was fixed as $10 \mathrm{~g} / \mathrm{L}$.

\section{Effect of contact time and initial dye concentration}

The contact time between the pollutant and the adsorbent is of significant importance in the wastewater treatment by adsorption (Akar and Tunali, 2005; Mall et al., 2006). In physical adsorption most of the adsorbate species are adsorbed within a short interval of contact time. However, strong chemical binding of the adsorbate with adsorbent requires a longer contact time for the attainment of equilibrium. Available adsorption studies in literature reveal that the uptake of adsorbate species is fast at the initial stages of the contact period, and thereafter, it becomes slower near the equilibrium. In between these two stages of the uptake, the rate of adsorption is found to be nearly constant. This is obvious from the fact that a large number of vacant surface sites are available for adsorption during the initial stage, and after a lapse of time, the remaining vacant surface sites are difficult to be occupied due to repulsive forces between the solute molecules on the solid and bulk phases (Mall et al., 2006). The effect of contact time under different initial dye concentrations ( 50 to $200 \mathrm{mg} / \mathrm{L}$ ) on the biosorption of RB 5 onto seed biosorbent is presented in Figure 4. RB 5 


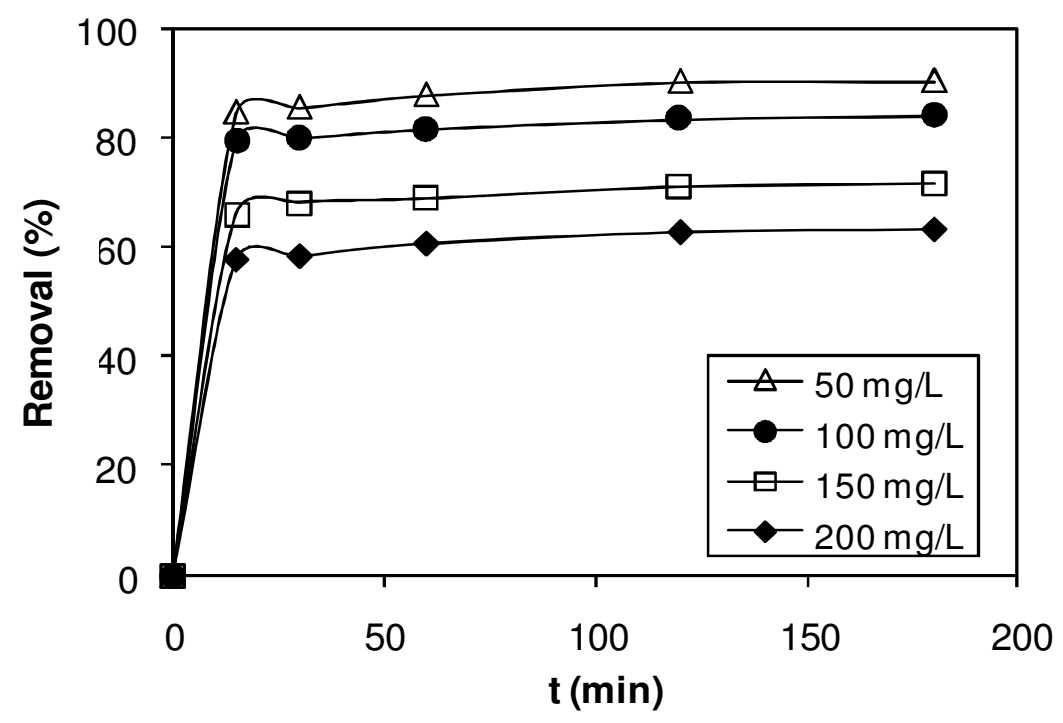

Figure 4. Effect of contact time on biosorption for RB $5(\mathrm{pH}=2.5, \mathrm{~m}=10 \mathrm{~g} / \mathrm{L})$.

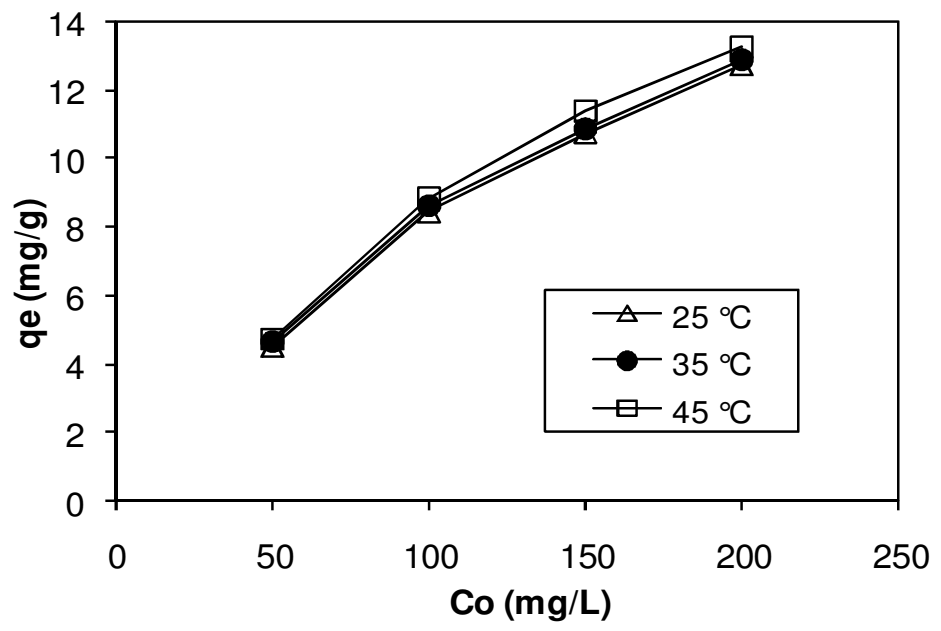

Figure 5. Effect of initial dye concentration and temperature on the biosorption of RB $5(\mathrm{pH}=2.5, \mathrm{~m}=10 \mathrm{~g} / \mathrm{L})$.

showed a fast rate of biosorption during the first $15 \mathrm{~min}$ of the dye-biosorbent contact. The fast step is probably due to the more available active sites on the sorbent at initial stage.

The initial concentration provides an important driving force to overcome all mass transfer resistances of all molecules between the aqueous and solid phases. But, the equilibrium time is independent of initial dye ions concentration. The equilibrium was reached within 180 min. After this equilibrium period, the amount of biosorbed dye did not show time-dependent change.

\section{Effect of initial dye concentration and temperature}

The effect of initial concentration of RB 5 in the solutions on biosorption was shown in Figure 5. Biosorption experiments were carried out at a fixed biosorbent dose of $10 \mathrm{~g} / \mathrm{L}$ and ranging from 50 to $200 \mathrm{mg} / \mathrm{L}$ RB 5 concentrations for different temperatures $\left(25\right.$ to $\left.45^{\circ} \mathrm{C}\right)$. As 
seen from Figure 5, equilibrium uptake increased simultaneously with the increase in initial RB 5 concentrations. Under the same conditions, if the concentration of RB 5 in the solution was higher, the active sites of seed biosorbent were surrounded by more RB 5 ions; the process of biosorption would carry out more sufficiently. Therefore, the values of $q_{\mathrm{e}}$ increased with the increase in initial RB 5 concentrations. The biosorption capacity increased from $12.69 \mathrm{mg} / \mathrm{g}$ at $25^{\circ} \mathrm{C}$ to $13.23 \mathrm{mg} / \mathrm{g}$ at $45^{\circ} \mathrm{C}$ for $200 \mathrm{mg} / \mathrm{L}$ dye concentration. It can be suggested that increase in biosorption capacity at increasing temperatures is due to either the higher affinity of sites for dye or an increase in binding sites onto the biosorbent. Similar results were reported for various dye adsorptions by other biosorbents (Erdem and Ozverdi, 2006; Rakhshaee et al., 2006; Sharma et al., 2007).

\section{Biosorption isotherms}

Analysis of equilibrium data is important for developing a model that can be used for the design of biosorption process. In the present study, two classical isotherm models (Langmuir and Freundlich) were used to describe the relationship between the amount of RB 5 adsorbed and its equilibrium concentration in solution. The Langmuir adsorption isotherm has been successfully applied to many pollutants sorption processes and has been the most widely used sorption isotherm for the sorption of a solute from a liquid solution (Vijayaraghan and Yun, 2008a, 2008b; Oladoja and Akinlabi, 2009). Langmuir isotherm equation is based on monolayer sorption onto a surface with finite number of identical sites, which are homogeneously distributed over the sorbent surface and is given by Equation 2 .

$q_{e}=\frac{Q_{\max } b C_{e}}{1+b C_{e}}$

The linear form of this equation can be given as:

$$
\frac{1}{q_{e}}=\left(\frac{1}{b q_{\max }}\right)\left(\frac{1}{C_{e}}\right)+\left(\frac{1}{q_{\max }}\right)
$$

Where, $q_{\max }$ and $b$ are Langmuir constants denoting maximum adsorption capacity and the affinity of the binding sites, respectively. These constants can be determined from the $1 / q_{\mathrm{e}}$ versus $1 / C_{\mathrm{e}}$. The Langmuir sorption isotherms of RB 5 obtained at 25,35 and $45^{\circ} \mathrm{C}$ are illustrated in Figure 6a. The values of $q_{\max }$ and $b$ estimated from the plots along with the correlation coefficients $\left(R^{2}\right)$ are presented in Table 1 . The values $q_{\max }$ and $b$ for the biosorption of RB 5 with loquat seed biosorbent are $13.76 \mathrm{mg} / \mathrm{g}$ and $0.101 \mathrm{~L} / \mathrm{g}$ for $25^{\circ} \mathrm{C}$, respectively. The value of Langmuir constant $b$ increased with temperature thereby suggesting that the dye molecules exhibited higher affinity for seed biosorbent at higher temperatures than at lower temperatures. High correlation coefficient $\left(R^{2}>0.997\right)$ were found at all the temperatures studied, suggesting that the Langmuir model was applicable. The essential features of a Langmuir isotherm can be expressed in terms of a dimensionless constant separation factor or equilibrium parameter, $R_{L}$ which is defined by Hall et al. (1966) as:

$$
R_{L}=1 /\left(1+b C_{o}\right)
$$

The value of $R_{L}$ indicates the shape of the isotherms to be either unfavourable $\left(R_{L}>1\right)$, linear $\left(R_{L}=1\right)$, favourable $\left(0<R_{L}<1\right)$. The $R_{L}$ values 0.047 and 0.030 while temperatures are 25 and $45^{\circ} \mathrm{C}\left(\mathrm{C}_{0}=200 \mathrm{mg} / \mathrm{L}\right)$, respectively (Table 1 ). All the $R_{L}$ values obtained using Equation 4 for RB 5 biosorption are greater than zero and less than unity showing favorable biosorption of RB 5 onto the loquat seed biosorbent. The Freundlich equation based on sorption on a heterogeneous surface is given below as Equation 5.

$q_{e}=K_{f} C_{e}^{1 / n}$

And linearized form of this model is:

$\log q_{e}=\log K_{f}+\left(\frac{1}{n}\right) \log C_{e}$

Where $K f$ and $n$ are Freundlich constants characteristic of the system. $K_{f}$ and $n$ are indicators of adsorption capacity and intensity, respectively. These constants can be determined from the linear plot of $\log q_{e}$ versus $\log C_{e}$ (Aksakal and Ucun, 2010). The linearized Freundlich adsorption isotherm of RB 5 obtained at different temperatures are shown in Figure 6b. The values of $K_{f}$ and $n$ estimated from the plots along with the correlation coefficients $\left(R^{2}\right)$ are presented in Table 1 . The $R^{2}$ value was found to be 0.96 . RB 5 biosorption from aqueous solutions by loquat seed biosorbent was better described by Langmuir model in comparison to Freundlich model since it presents higher $R^{2}$ value.

\section{Biosorption kinetics}

In order to investigate mechanism of biosorption, different 


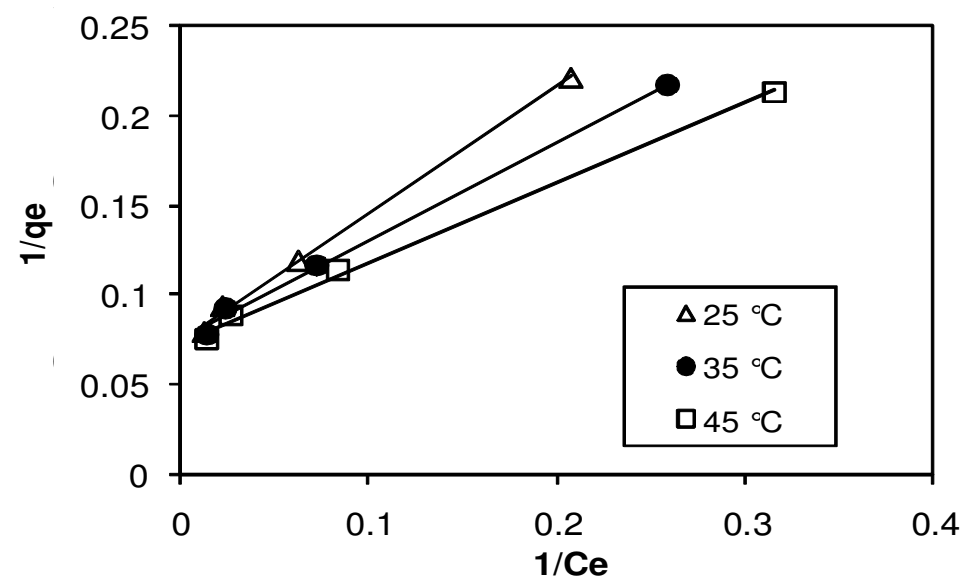

(a)

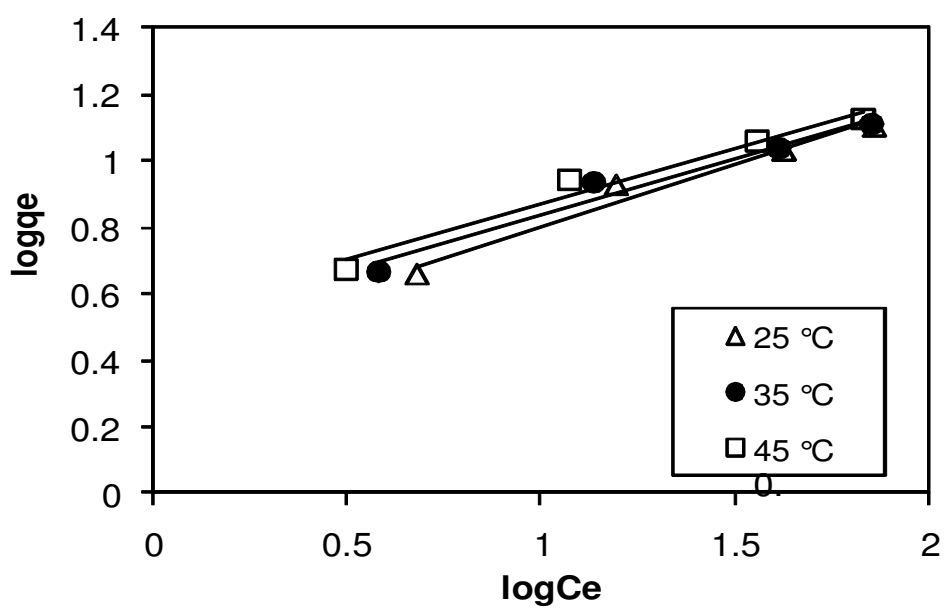

(b)

Figure 6. a) Langmuir isotherms and b) Freundlich isotherms obtained at different temperature values.

Table 1. Isotherm constants for RB 5 biosorption on loquat seed.

\begin{tabular}{cccccccc}
\hline \multicolumn{3}{c}{ Freundlich } & \multicolumn{4}{c}{ Langmuir } \\
\hline $\mathbf{T}^{\circ} \mathbf{C}$ & $\boldsymbol{K}_{\boldsymbol{f}}$ & $\boldsymbol{n}$ & $\boldsymbol{R}^{\mathbf{2}}$ & $\boldsymbol{Q}_{\max }(\mathbf{m g} / \mathbf{g})$ & $\boldsymbol{b}(\mathbf{L} / \mathbf{g})$ & $\boldsymbol{R}^{2}$ & $\boldsymbol{R}_{\mathbf{L}}\left(\mathbf{C}_{\mathbf{0}}=\mathbf{2 0 0} \mathbf{m g} / \mathbf{L}\right)$ \\
\hline 25 & 2.682 & 2.686 & 0.968 & 13.755 & 0.101 & 0.998 & 0.047 \\
35 & 3.110 & 2.929 & 0.964 & 13.369 & 0.136 & 0.997 & 0.035 \\
45 & 3.414 & 2.989 & 0.964 & 13.680 & 0.163 & 0.998 & 0.030 \\
\hline
\end{tabular}

kinetic models were used to describe the experimental data of biosorption. The pseudo-first-order model is:

$$
\mathrm{d} q / \mathrm{dt}=k_{1}\left(q_{e}-q_{t}\right)
$$

Where, $q_{t}(\mathrm{mg} / \mathrm{g})$ is the amount of adsorbed dye on the biosorbent at time $t$ and $k_{1}(1 / \mathrm{min})$ is the rate constant of first-order adsorption. The integrated form of Equation 7 is:

$$
q_{t}=q_{e}\left(1-\exp \left(-k_{1} t\right)\right)
$$




$$
\log \left(q_{e}-q_{t}\right)=\log q_{e}-\left(k_{1} / 2.303\right) t
$$

A straight line of $\log \left(q_{e}-q_{t}\right)$ versus $t$ suggests the applicability of this kinetic model. $q_{\mathrm{e}}$ and $k_{1}$ can be determined from the intercept and slope of the plot, respectively. Figure $7 \mathrm{a}$ shows the $\log (\mathrm{qe}-\mathrm{qt})$ versus $\mathrm{t}$ plots taking into account dye initial concentration for pseudo- first-order kinetic using loquat seed biosorbent in biosorption experiments. The rate constants $k_{1}$ were calculated from the slope of Figure 7a. It was observed that the rate constants $k_{1}$ decreased with the increase in the initial dye concentration. The correlation coefficients $\left(R^{2}\right)$ were low ranging from 0.712 to 0.899 (Table 2). On the other hand, the calculated equilibrium capacities $\left(q_{e}\right.$, cal) according to pseudo-first-order rate expression are not in agreement with the values of experimental capacities $\left(q_{e}, \quad\right.$ exp $)$ for solutions of the initial concentrations. The pseudo-second-order kinetic model has received considerable attention as a tool for quantitatively predicting the uptake of dyes from aqueous solutions. The pseudo-second-order kinetic model is expressed as follows:

$$
\frac{d q}{d t}=k_{2}\left(q_{e}-q_{t}\right)^{2}
$$

Where, $k_{2}(\mathrm{~g} / \mathrm{mg} \mathrm{min})$ is the rate constant of second-order adsorption. Equation 10 can be rearranged and linearized to obtain:

$$
\begin{aligned}
& q_{t}=\left(k_{2} t q_{e}^{2}\right) /\left(1+k_{2} t q_{e}\right) \\
& \frac{t}{q_{t}}=\frac{1}{k_{2}\left(q_{e}\right)^{2}}+\frac{t}{q_{e}}
\end{aligned}
$$

The nlot $t / a_{+}$versus $t$ should give a straight line if secondorde $h=k_{2}\left(q_{e}\right)^{2}$ applicable and $q_{e}$ and $k_{2}$ can be respectively.

$h=k_{2}\left(q_{e}\right)^{2}$

Where, $h$ is the initial sorption rate $(\mathrm{mg} / \mathrm{g} \mathrm{min}$ ) (Ho and McKay, 1999).

The pseudo-second-order kinetic biosorption rate constant $k_{2}$ and $q_{e}$ values were determined from the slope and intercept of the plots of $t / q t$ against time $t$ (Figure $7 \mathrm{~b}$ ). The values of the rate constant are presented in Table 2 along with the correlation coefficient. From Table 2 it can be observed that an increase in initial dye concentration caused an increase in the equilibrium biosorption capacity, qe and initial biosorption rate, $h$ (except for $\mathrm{Co}=200$ ), but reduced the biosorption rate, $k_{2}$. It is also observed from Table 2 that the values for $R^{2}$ in pseudo-second-order were 0.999, which is much higher than $R^{2}$ of the pseudo-first-order values. The higher values of $R^{2}$ and the calculated values of equilibrium sorption capacity, qe, which is very much in agreement with experimental data for all initial RB 5 concentrations, confirms that the biosorption process follows a pseudo-second-order mechanism. Similar kinetic results were also found in the biosorption of RB 5 on acid-treated biosorbent of brown seaweed Laminaria sp. (Vijayaraghan and Yun, 2008) and Aspergillus foetidus biosorbent (Patel and Suresh, 2008). The Elovich equation can be written in the following form:

$$
d q_{t} / d t=\alpha \exp \left(-\beta q_{t}\right)
$$

Where, $\alpha$ is the initial adsorption rate $(\mathrm{mg} / \mathrm{g} \mathrm{min})$ and the parameter $\beta$ is desorption constant $(\mathrm{g} / \mathrm{mg})$. These coefficients are computed from the plots of $q_{t}$ versus $\ln t$. The integrated form of Equation 14 is:

$q_{t}=(1 / \beta) \ln (\alpha \beta)+(1 / \beta) \ln (t)$

When the adsorbate ions and the surface sites interact chemically through a second-order mechanism, the application of the Elovich equation may be more appropriate (Ho and McKay, 1998). Figure 7c shows a plot of $q_{t}$ versus In $t$ for the Elovich equation at different dye concentrations. Table 2 lists the kinetic constants obtained from the Elovich equation. The Elovich equation describes predominantly chemical adsorption on highly heterogeneous adsorbents but the equation does not propose any definite mechanism for adsorbate-adsorbent interaction. The coefficients are significantly depending on the amount of adsorbent with a being much more sensitive (Ho and McKay, 1998). Most adsorption reactions take place through multi step mechanism comprising: i) external film diffusion, ii) intraparticle diffusion and iii) interaction between adsorbate and active site. Since the first step is excluded by shaking the solution, the rate-determining step is one of the other two steps. Weber and Morris (1963) described the intraparticle uptake of the adsorption process to be proportional to the half-power of time:

$q_{t}=k_{i}(t)^{1 / 2}+C$ 

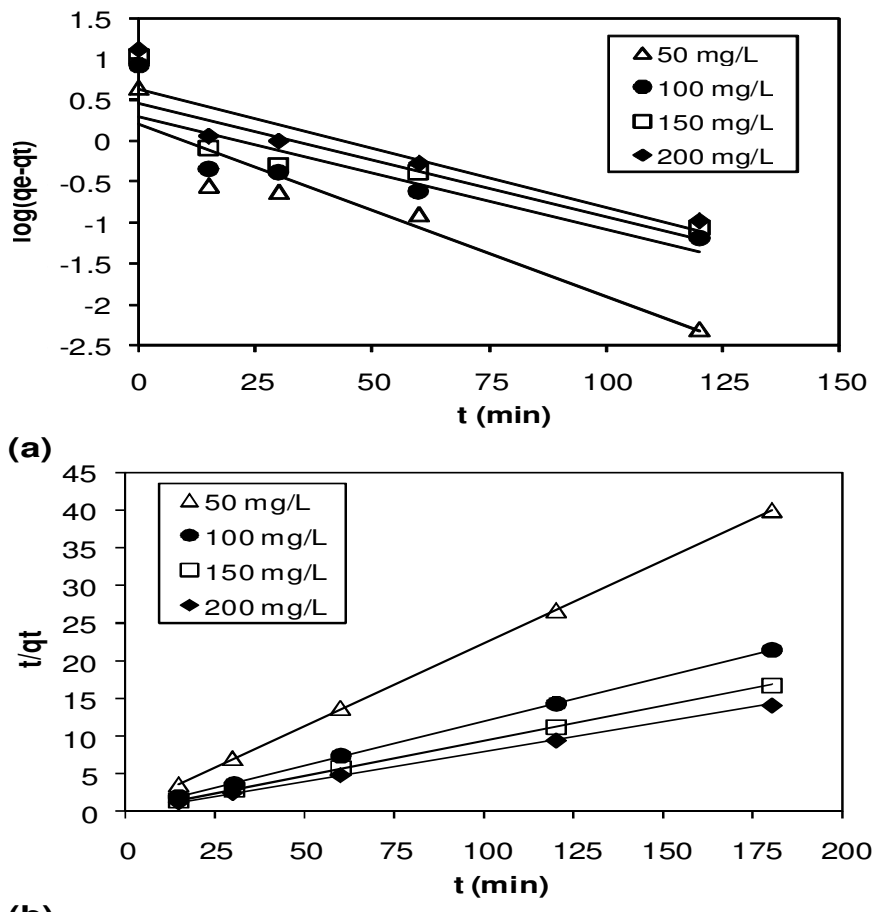

(b)

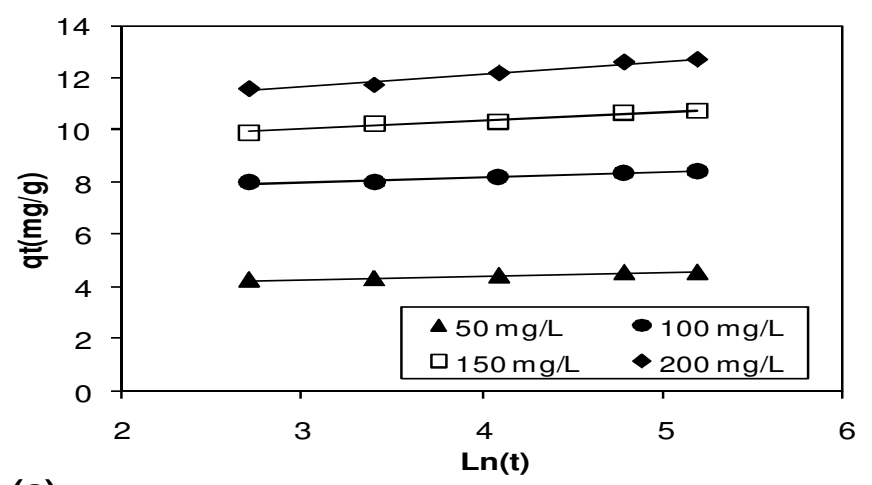

(c)

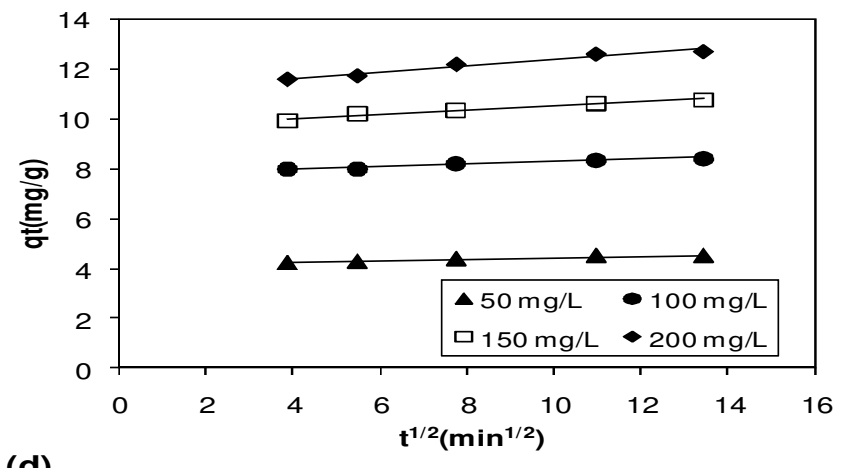

(d)

Figure 7. Plots biosorption kinetic equations, a) the pseudo-firstorder and b) the pseudo-second-order biosorption kinetics of RB 5 at different temperatures, c) the Elovich equation and d) the intrapaticle diffusion kinetic for RB 5 bisorption at $25^{\circ} \mathrm{C}$.
Where, $k_{i}$ is the intraparticle diffusion rate constant $(\mathrm{mg} / \mathrm{g}$ $\min ^{0.5}$ ) and $C$ is the intercept.

According to the Weber-Morris model, the plot of $q_{t}$ versus $t^{0.5}$ should be linear if intraparticle diffusion is involved in the biosorption process and if this line passes through the origin, then intraparticle diffusion is the rate controlling step. The process involves more than one kinetic stage. The first can be attributed to biosorption of dye over the biomass surface and hence it was the fastest biosorption stage. The second ascribed to the intraparticle diffusion was also relatively fast. The third stage may be regarded as the diffusion through smaller pores which was followed by the establishment of equilibrium (Vijayaraghavan et al., 2007). Figure 7d shows that the straight-line portion does not pass through the origin. Values of $C$ and $k_{i}$, are given in Table 2 for all dye concentration. The values of intraparticle diffusion rates $\left(k_{i}\right)$ estimated from the slopes increased from 0.0328 to $0.126 \mathrm{mg} /\left(\mathrm{g} \mathrm{min}^{0.5}\right)$ with the increasing initial concentration from 50 to $200 \mathrm{mg} / \mathrm{L}$ for seed biosorbent. The values of $R^{2}$ changed from 0.946 to 0.984 . As can be seen from Table 2, the pseudo-second-order and the Elovich chemisorption models are suitably fitted.

\section{Thermodynamic parameters}

To evaluate the effect of temperature on the biosorption of RB 5 onto loquat seed biosorbent, the free energy change $\left(\Delta G^{\circ}\right)$, enthalpy change $\left(\Delta H^{\circ}\right)$ and entropy change $\left(\Delta S^{\circ}\right)$ were determined using the following equations:

$$
\Delta G^{o}=-R T \ln K_{c}
$$

Where $\mathrm{R}$ is the gas constant $(8.314 \mathrm{~J} / \mathrm{Kmol}), K_{c}$ is the adsorption equilibrium constant and $T$ is absolute temperature. Relation between $\Delta G^{\circ}, \Delta H^{\circ}$ and $\Delta S^{\circ}$ can be expressed by the following equations:

$$
\Delta G^{o}=\Delta H^{o}-T \Delta S^{o}
$$

Equation 18 can be written as:

$$
\ln K_{c}=\Delta S^{o} / R-\Delta H^{o} /(R T)
$$

Where the values of $\Delta H^{\circ}$ and $\Delta S^{\circ}$ can be determined from the slope and intercept of the plot between $\ln K_{c}$ versus $1 / T$ (Figure 8 ). The values of $\Delta G^{\circ}, \Delta H^{\circ}$ and $\Delta S^{\circ}$ for the biosorption of RB 5 onto given in Table 3 .

The free energy of the process at all seed biosorbent at 
Table 2. Kinetic parameters for biosorption of RB 5 on loquat seed.

\begin{tabular}{|c|c|c|c|c|c|c|c|c|c|c|c|c|c|c|}
\hline \multirow[b]{2}{*}{ Co } & \multirow[b]{2}{*}{$q e \exp$} & \multirow[b]{2}{*}{$k_{1}(1 / \mathrm{min})$} & \multicolumn{2}{|c|}{ Pseudo-first-order } & \multicolumn{4}{|c|}{ Pseudo-second-order } & \multicolumn{3}{|c|}{ Intraparticle diffusion model } & \multicolumn{3}{|c|}{ Elovich equation } \\
\hline & & & qe.cal (mg/g) & $R^{2}$ & qe & $k_{2}$ (g/mgmin) & $\boldsymbol{h}$ & $R^{2}$ & $k_{i}(\mathrm{mg} / \mathrm{g} \min 1 / 2)$ & C & $R^{2}$ & $\beta(\mathrm{g} / \mathrm{mg})$ & $\alpha(\mathrm{mg} / \mathrm{g} \mathrm{min}) \times 10^{10}$ & $R^{2}$ \\
\hline 50 & 4.52 & 0.049 & 1.621 & 0.899 & 4.56 & 0.1263 & 2.6295 & 0.999 & 0.0328 & 4.1138 & 0.946 & 7.7821 & 150.763 & 0.968 \\
\hline 100 & 8.42 & 0.032 & 1.991 & 0.712 & 8.48 & 0.0718 & 5.1680 & 0.999 & 0.0517 & 7.7559 & 0.984 & 5.0150 & 236154 & 0.975 \\
\hline 150 & 10.73 & 0.032 & 2.925 & 0.754 & 10.83 & 0.0466 & 5.4705 & 0.999 & 0.0833 & 9.6737 & 0.948 & 3.0488 & 30.6371 & 0.979 \\
\hline 200 & 12.68 & 0.031 & 4.169 & 0.816 & 12.87 & 0.0303 & 5.0176 & 0.999 & 0.1260 & 11.111 & 0.964 & 2.0392 & 0.05039 & 0.974 \\
\hline
\end{tabular}

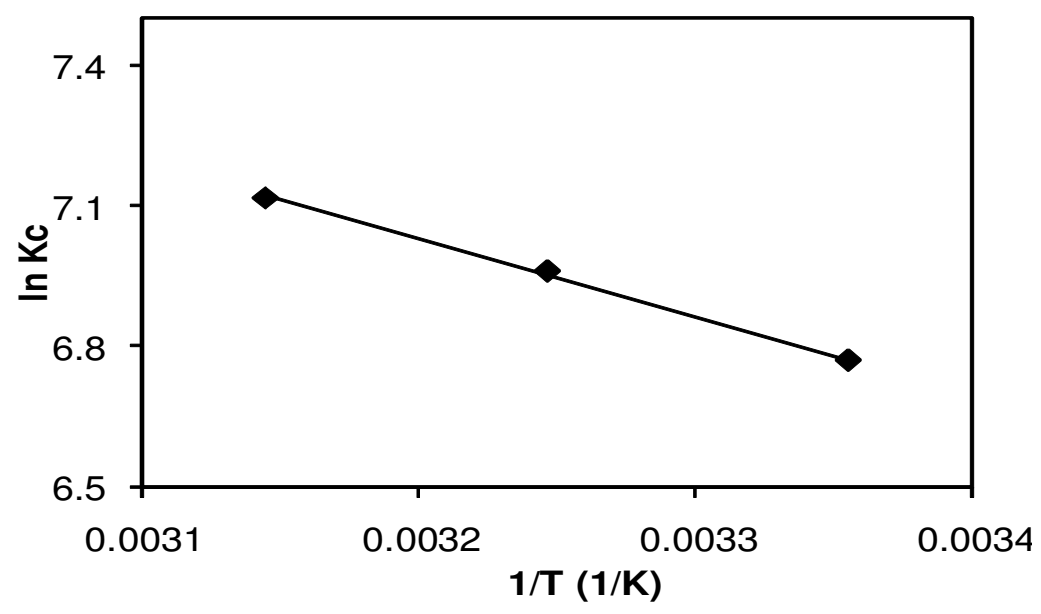

Figure 8. In $K_{c}$ versus $1 / T$ plot

different temperatures are temperatures was negative and changed with the rise in temperature. This indicates that the biosorption process was spontaneous and thermodynamically favorable. The more negative values of $\Delta G^{\circ}$ imply a greater driving force for the biosorption process. As the temperature increased, the $\Delta G^{\circ}$ value decreased indicating a lower driving force resulting in a lesser biosorption capacity at higher temperatures. The value of $\Delta H^{\circ}$ is positive, indicating that the biosorption reaction is endothermic. This is also supported by the increase in the value of uptake capacity of the biosorbent with the rise in temperature. The positive value of $\Delta S^{\circ}$ reflects the affinity of RB5 for the biosorbent used. In addition, positive value of
$\Delta S^{\circ}$ shows the increasing randomness at the solid/liquid interface during the biosorption of RB5 on the selected biosorbent.

\section{Conclusions}

Equilibrium, kinetic and thermodynamic studies of 
Table 3. Thermodynamic parameters for the biosorption of RB 5 on loquat seed.

\begin{tabular}{cccc}
\hline $\mathbf{T}^{\circ} \mathbf{C}$ & $\boldsymbol{\Delta \boldsymbol { G } ^ { \boldsymbol { 0 } } ( \mathrm { kJ } / \mathrm { mol } )}$ & $\boldsymbol{\Delta} \boldsymbol{H}^{\boldsymbol{0}}(\mathrm{kJ} / \mathrm{Kmol})$ & $\boldsymbol{\Delta S}^{\boldsymbol{0}}(\mathrm{J} / \mathrm{Kmol})$ \\
\hline 25 & -16.770 & & \\
35 & -17.823 & 13.754 & 102.462 \\
45 & -18.818 & & \\
\hline
\end{tabular}

the biosorption of RB 5 ions onto the loquat seed biosorbent revealed that the biosorbent could be used to remove the dye from aqueous solution. This study showed that $\mathrm{pH}$, biosorbent dose, time, initial dye concentration and temperature affected the biosorption process. The optimum $\mathrm{pH}$ for efficient biosorption of RB 5 was 2.5. The equilibrium data were evaluated by using Langmuir and Freundlich isotherms and the Langmuir isotherm was found to provide the best correlation of the experimental data. Thermodynamic parameters including the Gibbs free energy, enthalpy and entropy changes indicated that the biosorption of RB 5 onto loquat seed biosorbent was feasible, spontaneous and endothermic. The results revealed that loquat seed biosorbent could be used as biosorbent for the treatment of wastewater containing RB 5.

\section{REFERENCES}

Akar T, Tunali S (2005): Biosorption performance of Botrytis cinerea fungal by-products for removal of $\mathrm{Cd}(\mathrm{II})$ and $\mathrm{Cu}$ (II) ions from aqueous solutions, Miner. Eng., 18: 1099-1109.

Aksakal O, Ucun H, Kaya Y (2009). Application of Eriobotrya japonica (Thunb.) Lindley (Loquat) seed biomass as a new biosorbent for the removal of malachite green from aqueous solution, Water. Sci. Technol., 59: 1631-1639.

Aksakal O, Ucun H (2010). Equilibrium, kinetic and thermodynamic studies of the biosorption of textile dye (Reactive Red 195) onto Pinus sylvestris L., J. Hazard. Mater., 181: 666-672.

Aksu Z, Isoglu IA (2006). Use of agricultural waste sugar beet pulp for the removal of Gemazol turquoise blue-G reactive dye from aqueous solution, J. Hazard. Mater., 137: 418-430.

Chowdhury AK, Sarakar AD, Bandyopadhyay A (2009). Rice husk ash as a low cost adsorbent for the removal of methylene blue and congo red in aqueous phases, CLEAN-Soil Air Water., 37: 581-591.

Cicek F, Ozer D, Ozer A, Ozer A (2007). Low cost removal of reactive dyes using wheat bran, J. Hazard. Mater., 146: 408-416.

Erdem M, Ozverdi A (2006). Kinetics and thermodynamics of Cd(II)

adsorption onto pyrite and synthetic iron sulphide, Sep. Purif. Technol., 51: 240-246.

Femenia A, García-Conesa M, Simal S, Rossello C (1998). Characterization of the cell walls of loquat (Eriobotrya japonica L.) fruit tissues, Carbohydr. Polym., 35: 169-177.

FuY, Viraraghavan T. (2001). Fungal decolourization of dye wastewaters: a review, Bioresour. Technol., 79: 251-262.

Hall KR, Eagleton LC, Acrivos A, Vermeulen T (1966). Pore and solid diffusion kinetics in fixed-bed adsorption under constant pattern conditions, Ind. Eng. Chem. Fundam., 5: 212-223.
Hameed BH, Mahmoud DK, Ahmad AL (2008). Sorption of basic dye from aqueous solution by pomelo (Citrus grandis) peel in a batch system, Colloids Surf. A: Physicochem. Eng. Asp., 316: 78-84.

Ho YS, McKay G (1998). A comparison of chemisorption kinetic models applied to pollutant removal on various sorbents, Process Safety and Environmental Protection, 76: 332-340.

Ho YS, McKay G (1999). Pseudo-second order model for sorption processes, Process Biochem., 34: 451-465.

Lin G, Han S, Li Z (1999). Enzymatic synthesis of (R)-cyanohydrins by three (R)-oxynitrilase sources in microaqueous organic medium, Tetrahedron., 55: 3531-3540.

Lin S (2007). World loquat production and research with special reference to China, Acta Hortoculturae., 750: 37-43.

Mall ID, Srivastava VC, Agarwal NK (2006). Removal of Orange-G and Methyl Violet dyes by adsorption onto bagasse fly ashdkinetic study and equilibrium isotherm analyses, Dyes Pigments, 69: 210-223.

Mishra G, Tripathy M. (1993). A critical review of the treatment for decolourization of textile effluent, Colourage, 40: 35-38.

Oladoja NA, Akinlabi AK (2009). Congo red biosorption on palm kernel seed coat, Ind. Eng. Chem. Res., 48: 6188-6196.

Ozacar M, Sengil IA (2005). Adsorption of metal complex dyes from aqueous solution by pine sawdust, Bioresour. Technol., 96: 791-795.

Patel R, Suresh S (2008). Kinetic and equilibrium studies on the biosorption of reactive black 5 dye by Aspergillus foetidus, Bioresour. Technol., 99: 51-58.

Prasad MNV, Freitas HMO (2003). Metal hyperaccumulation in plantsbiodiversity prospecting for phytoremediation technology, Electron. J. Biotechnol., 6: 285-291.

Rao RAK, Khan MA (2009). Biosorption of bivalent metal ions from aqueous solution by an agricultural waste: Kinetics, thermodynamics and environmental effects, Colloids Surf. A: Physicochem. Eng. Asp., 332: 121-128.

Rakhshaee R, Khosravi M, Ganji MT (2006). Kinetic modeling and thermodynamic study to remove $\mathrm{Pb}(\mathrm{II}), \mathrm{Cd}(\mathrm{II}), \mathrm{Ni}(\mathrm{II})$ and $\mathrm{Zn}$ (II) from aqueous solution using dead and living Azolla filiculoides, J. Hazard. Mater., 134: 120-129.

Renganathan S, Kalpana J, Kumar MD, Velan M (2009). Equilibrium and kinetic studies on the removal of reactive red 2 dye from an aqueous solution using a positively charged functional group of the Nymphaea rubra biosorbent, CLEAN-Soil Air Water, 37: 901-907.

Robinson T, Mcmullan G, Marchant R, Nigam P. (2001). Remediation of dyes in textile effluent: a critical review on current treatment technologies with a proposed alternative, Bioresour. Technol., 77: 247-255.

Sadettin S, Dönmez G (2006). Bioaccumulation of reactive dyes by thermophilic cyanobacteria, Process. Biochem., 41: 836-841.

Sharma YC, Kaul SN, Weng CH (2007): Adsorptive separation of cadmium from aqueous solutions and wastewaters by riverbed sand, Environ. Pollut., 150: 251-257.

Vijayaraghavan K, Han MH, Choi SB, Yun YS (2007). Biosorption of Reactive black 5 by Corynebacterium glutamicum biomass immobilized in alginate and polysulfone matrices, Chemosphere, 68: $1838-1845$ 
Vijayaraghavan K, Yun YS (2008a). Biosorption of C.I. Reactive black 5 from aqueous solution using acid-treated biomass of brown seaweed Laminaria sp., Dyes Pigments. 76: 726-732.

Vijayaraghavan K, Yun YS (2008b). Bacterial biosorbents and biosorption, Biotechnol. Adv,. 26: 266-291.

Wang S, Boyjoo Y, Choueib A, Zhu ZH (2005). Removal of dyes from aqueous solution using fly ash and red mud, Water Res., 39: 129138.
Weber WJ, Morris JC (1963). Kinetics of adsorption on carbon solution, J. San. Eng. Div. ASCE, 89: 31-59.

Zhang HZ, Peng SA, Cai LH, Fang DQ (1993). The germplasm resources of the genus Eryobotria with special reference on the origin of E. japonica Lindl., Plant Breed Abstr., 63: 772-777. 